\title{
Lithium metasilicate and lithium disilicate nanomaterials: optical properties and density functional theory calculations
}

\author{
Abdolali Alemi', Shahin Khademinia ${ }^{*}$, Sang Woo Joo ${ }^{2}$, Mahboubeh Dolatyari $^{3}$ and Akbar Bakhtiari ${ }^{4}$
}

\begin{abstract}
UV-vis and photoluminescence spectra of the hydrothermally synthesized crystalline lithium metasilicate $\left(\mathrm{Li}_{2} \mathrm{SiO}_{3}\right)$ and lithium disilicate $\left(\mathrm{Li}_{2} \mathrm{Si}_{2} \mathrm{O}_{5}\right)$ nanomaterials are studied. The intensity of the bands in the emission spectra increases with increasing reaction time in both compounds. The electronic band structure along with density of states calculated by the density functional theory (DFT) method indicates that $\mathrm{Li}_{2} \mathrm{SiO}_{3}$ and $\mathrm{Li}_{2} \mathrm{Si}_{2} \mathrm{O}_{5}$ have an indirect energy band gap of 4.575 and $4.776 \mathrm{eV}$ respectively. The optical properties, including the dielectric, absorption, reflectivity, and energy loss spectra of the compounds, are calculated by DFT method and analyzed based on the electronic structures.
\end{abstract}

Keywords: Lithium silicates, Nanomaterials, Optical properties, DFT calculations

\section{Background}

Silicates are the most abundant and most complicated class of minerals on earth that have tremendous technological applications in fields such as catalysis, microelectronics, biomedicine, photonics, and traditional glass and ceramic industries [1]. In particular, the crystalline lithium silicates are present as important phases in silicate glass ceramics [2] and are of research interest because of their technological applications in areas such as $\mathrm{CO}_{2}$ captures [3-12], lithium battery cathode materials [13], fast ion conductors [14], optical waveguides [15], and tritium breeding materials $[16,17]$.

Synthesis of lithium silicates has been achieved using different methods, such as solid state reaction, precipitation, sol-gel method, extrusion-spherodisation process, rotating/melting procedures, combustion, electrochemical method, and recently via hydrothermal method. However, most of the time, a mixture of $\mathrm{Li}_{2} \mathrm{SiO}_{3}, \mathrm{Li}_{2} \mathrm{Si}_{2} \mathrm{O}_{5}, \mathrm{Li}_{4} \mathrm{SiO}_{4}$, and $\mathrm{SiO}_{2}$ were obtained [13,15,18-21]. On the other hand, the synthesis of nanocrystalline ceramic materials imposes a challenge on the traditional solid state synthesis methods which fail to offer a sufficiently narrow size distribution

\footnotetext{
*Correspondence: shahinkhademinia@gmail.com

'Department of Inorganic Chemistry, Faculty of Chemistry, University of Tabriz, Tabriz, Iran

Full list of author information is available at the end of the article
}

and desired homogeneity at the nanometer level [22]. However, the hydrothermal synthesis method has an advantage for the production of highly crystalline and pure nanoparticles [23].

Moreover, despite of some significant experimental achievements, our knowledge on the electronic structure and optical properties of the crystalline lithium silicates is still rather limited. The electronic structure of the lithium metasilicate $\left(\mathrm{Li}_{2} \mathrm{SiO}_{3}\right)$ and lithium disilicates $\left(\mathrm{Li}_{2} \mathrm{Si}_{2} \mathrm{O}_{5}\right)$ are previously calculated [1]. However, the predicted band gaps are wider than even those experimentally measured for the related nanocrystals described in this research work. Moreover, the optical properties of these materials are not calculated.

Recently, we have reported the synthesis of highly crystalline and pure lithium metasilicate and lithium disilicate nanomaterials through a mild condition via hydrothermal method [24]. Herein, we will report the powder X-ray diffraction (PXRD) and scanning electron microscopy (SEM) analysis results in more details. In addition, the UV-vis and photoluminescence spectra of the obtained materials will be discussed. Moreover, we will present the electronic and optical properties of the synthesized materials through the density functional theory calculations. 


\section{Methods}

The synthesis procedures are reported previously [24]. Phase identifications were performed on a powder X-ray diffractometer Siemens D5000 (Siemens AG, Munich, Germany) using $\mathrm{Cu}-K_{\alpha}$ radiation. The morphology of the obtained materials was examined with a Philips XL30 scanning electron microscope (North Billerica, MA, USA). Absorption and photoluminescence spectra were recorded on a Jena Analytik Specord 40 (AnalytikJena UK, Wembley, UK) and a PerkinElmer LF-5 spectrometer (PerkinElmer, Waltham, MA, USA) respectively.

\section{Computational details}

The electronic band structures along with the density of states (DOS) of the compounds are calculated by density functional theory (DFT) using one of the three non-local gradient-corrected exchange-correlation functionals (generalized gradient approximation-Perdew-Burke-Ernzerhof parametrization, GGA-PBE). Calculations were performed with the CASTEP code $[25,26]$, which uses a plane wave basis set for the valence electrons and norm-conserving pseudopotential [27] for the core electrons. The number of plane waves included in the basis was determined by a cutoff energy Ec of $500.0 \mathrm{eV}$. The summation over the Brillouin zone was carried out with a $k$-point sampling using a Monkhorst-Pack grid [28] with parameters of $5 \times$ $5 \times 5$ and $4 \times 5 \times 2$ for $\mathrm{Li}_{2} \mathrm{SiO}_{3}$ and $\mathrm{Li}_{2} \mathrm{Si}_{2} \mathrm{O}_{5}$, respectively. Pseudoatomic calculations were performed for $\mathrm{Li}-2 s^{2}, \mathrm{Si}-3$ $s^{2} 3 p^{2}, \mathrm{O}-2 s^{2} 2 p^{4}$. The parameters used in the calculations and convergence criteria were set by the default values of the CASTEP code, e.g., reciprocal space pseudo-potentials representations, eigen-energy convergence tolerance of $1 \times 10^{-6} \mathrm{eV}$, Gaussian smearing scheme with the smearing width of $0.1 \mathrm{eV}$, and Fermi energy convergence tolerance of $1 \times 10^{-7} \mathrm{eV}$.

\section{Results and discussion PXRD analysis}

Figure 1 represents the PXRD patterns of the obtained $\mathrm{Li}_{2} \mathrm{SiO}_{3}$ nanomaterials after reaction times of 48,72 , and $96 \mathrm{~h}$. The PXRD measurements confirm that when the $\mathrm{Li} / \mathrm{Si}$ molar ratio in the reaction mixture is $1: 2$, a pure phase of the orthorhombic $\mathrm{Li}_{2} \mathrm{SiO}_{3}$ (space group of $\mathrm{Cmc2}_{1}$ [29-35]) is formed. In contrast, as shown in Figure 2, with the $\mathrm{Li} / \mathrm{Si}$ molar ratio of $1: 3$ in the reaction mixture, a mixture of meta-stable $\mathrm{Li}_{2} \mathrm{Si}_{2} \mathrm{O}_{5}$ (space group of Pbcn [36,37]) and $\mathrm{Li}_{2} \mathrm{SiO}_{3}$ is obtained after $48 \mathrm{~h}$. By increasing the reaction time to 72,96 , or $120 \mathrm{~h}$, a pure highly crystalline phase of meta-stable $\mathrm{Li}_{2} \mathrm{Si}_{2} \mathrm{O}_{5}$ is obtained. A stable form of this compound crystallizes in the space group of $C c c 2$ [38]. However, most papers refer to a monoclinic cell [19,39-43] despite noticing a discrepancy in diffraction peak intensities between the experiment and calculation. The monoclinic cell has a

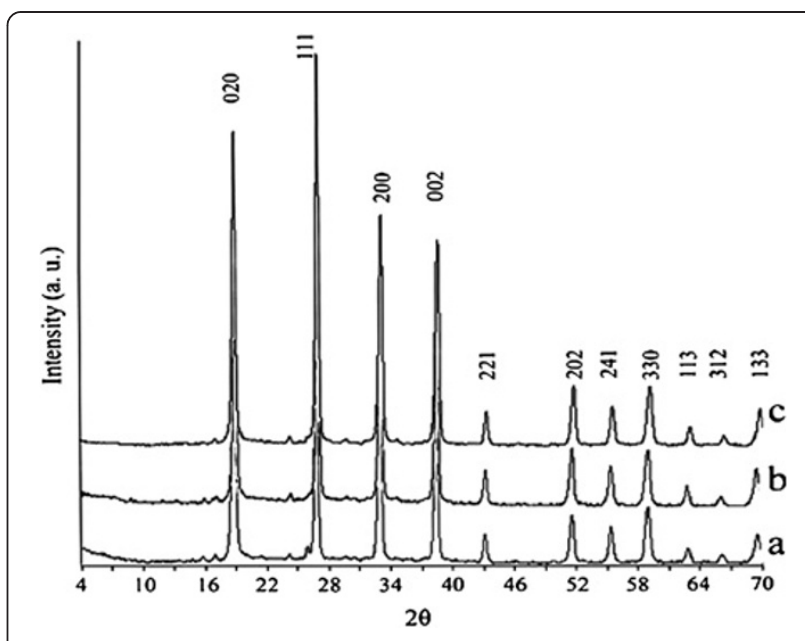

Figure 1 PXRD patterns of the synthesized $\mathrm{Li}_{2} \mathrm{SiO}_{3}$ nanomaterials after different times at $180^{\circ} \mathrm{C}$. (a) 48 , (b) 72 , and (c) $96 \mathrm{~h}$.

different symmetry but the same size as the $C c c 2$ stable form $\left(\beta=90^{\circ}\right)$ [44]. Particle sizes that were measured via Debye-Sherrer equation are as follows: Lithium metasilicate particle sizes are 26.12, 26.82, and $24.58 \mathrm{~nm}$ for 48,72 , and $96 \mathrm{~h}$ reaction times, respectively. Lithium disilicate particle sizes are 20.696, 22.50, and $23.86 \mathrm{~nm}$ for 72,96 , and $120 \mathrm{~h}$ reaction times, respectively. Also, interplanar spacing in the crystalline material are calculated via Bragg's law $\left(n \lambda=2 \mathrm{~d}_{\mathrm{hkl}}\right.$ $\sin \theta)$ ). Thus compared to those of the nanoparticles of pure lithium silicates, with increasing the reaction time, the diffraction lines in the powder XRD patterns of the nanoparticles of lithium metasilicates shift to higher $2 \theta$ values $\left(\Delta 2 \theta=26.84(48 \mathrm{~h})-26.88(96 \mathrm{~h})=0.04^{\circ}\right.$ and $\Delta \mathrm{d}=3.3177 \AA(48 \mathrm{~h})-3.3128 \AA(96 \mathrm{~h})=0.0049 \AA$; and with increasing the reaction time, the diffraction lines in

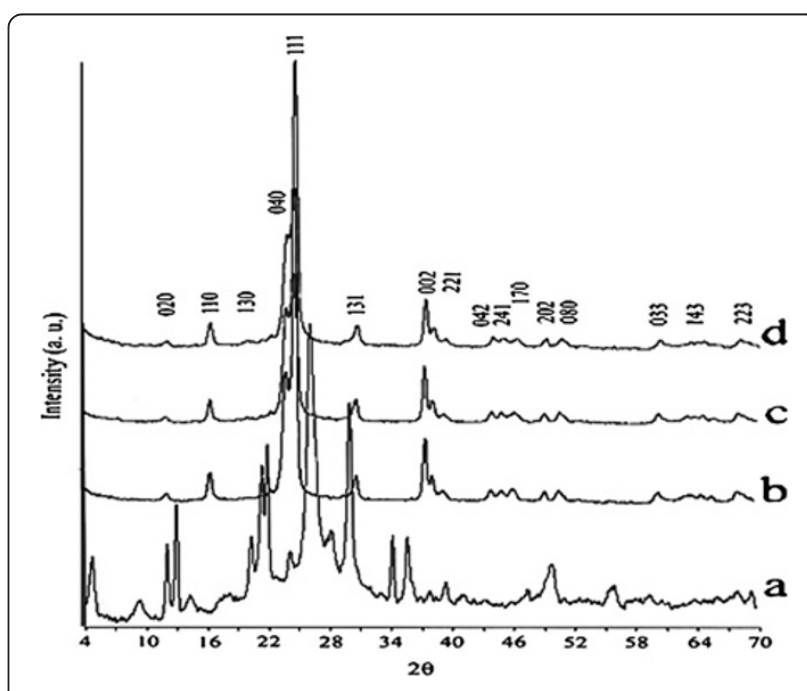

Figure 2 PXRD patterns of the synthesized $\mathrm{Li}_{2} \mathrm{Si}_{2} \mathrm{O}_{5}$ nanomaterials after different times at $180^{\circ} \mathbf{C}$. (a) 48 , (b) 72 , (c) 96 , and (d) $120 \mathrm{~h}$. 
the powder XRD patterns of the nanoparticles of lithium disilicates shift to lower $2 \theta$ values $\Delta 2 \theta=30.66(72 \mathrm{~h})-$ $30.59(120 \mathrm{~h})=0.07^{\circ}, \Delta \mathrm{d}=2.9190 \AA(120 \mathrm{~h})-2.9125 \AA$ $(72 \mathrm{~h})=0.065 \AA$. According to above measurements, particle sizes measured with Debye-Sherrer equation are in good agreement with interplanar spacing in the crystalline material measured via Bragg's law.

\section{Microstructure analysis}

The SEM images of the synthesized $\mathrm{Li}_{2} \mathrm{SiO}_{3}$ nanomaterials are given in Figure 3. With the reaction time of $48 \mathrm{~h}$, ununiform sheet-like nanoparticles of $\mathrm{Li}_{2} \mathrm{SiO}_{3}$ are obtained (Figure 3a). The thicknesses, widths, and lengths of the resultant sheets are approximately $100 \mathrm{~nm}, 600 \mathrm{~nm}$ and $2 \mu \mathrm{m}$, respectively. With increasing the reaction time to $72 \mathrm{~h}$, the morphology of the obtained materials has been changed to the very compact sheets with heterogeneous morphology (Figure 3b). This is while with the reaction time of $96 \mathrm{~h}$, uniform flower-like nanoparticles are obtained (Figure 3c).

Figure 4 represents the SEM images of the synthesized $\mathrm{Li}_{2} \mathrm{Si}_{2} \mathrm{O}_{5}$ nanomaterials. After $48 \mathrm{~h}$, the morphology of the obtained material is sponge-like, consisting of sheet-like and flower-like nanoparticles (Figure 4a). With increasing the reaction time to 72,96 , and $120 \mathrm{~h}$, the morphology of the obtained materials has been changed to the rectangular sheets and high homogeny in the size is achieved. According to Figure 3 with image magnification of 15,000, it is clear that with increasing reaction time, the grain size has been decreased. Moreover, according to Figure 4, with image magnification of 15,000 , it is clear that with increasing the reaction time the grain size has been increased. So Figures 3 and 4 are in agreement with the calculated particle size and interplanar spacing in the crystalline material measured in PXRD analysis section.

\section{Spectroscopic studies}

The electronic absorption spectra and also the emission spectra of the synthesized $\mathrm{Li}_{2} \mathrm{SiO}_{3}$ and $\mathrm{Li}_{2} \mathrm{Si}_{2} \mathrm{O}_{5}$ nanomaterials are given in Figures 5 and 6, respectively. An intense absorption band at 276, 275, and $275 \mathrm{~nm}$ is observed in the electronic absorption spectra of the $\mathrm{Li}_{2} \mathrm{SiO}_{3}$ nanomaterials obtained after 48,72 , and $96 \mathrm{~h}$ at $180^{\circ} \mathrm{C}$ respectively. A similar intense absorption band is observed at 272, 274, and $277 \mathrm{~nm}$ in the electronic absorption spectra of the $\mathrm{Li}_{2} \mathrm{Si}_{2} \mathrm{O}_{5}$ nanomaterials obtained after 48,72 , and $96 \mathrm{~h}$ at $180^{\circ} \mathrm{C}$, respectively.

In the excitation spectrum of the synthesized $\mathrm{Li}_{2} \mathrm{SiO}_{3}$ and $\mathrm{Li}_{2} \mathrm{Si}_{2} \mathrm{O}_{5}$ nanomaterials, a band is observed with maxima at 360 and $250 \mathrm{~nm}$, respectively. Accordingly, in

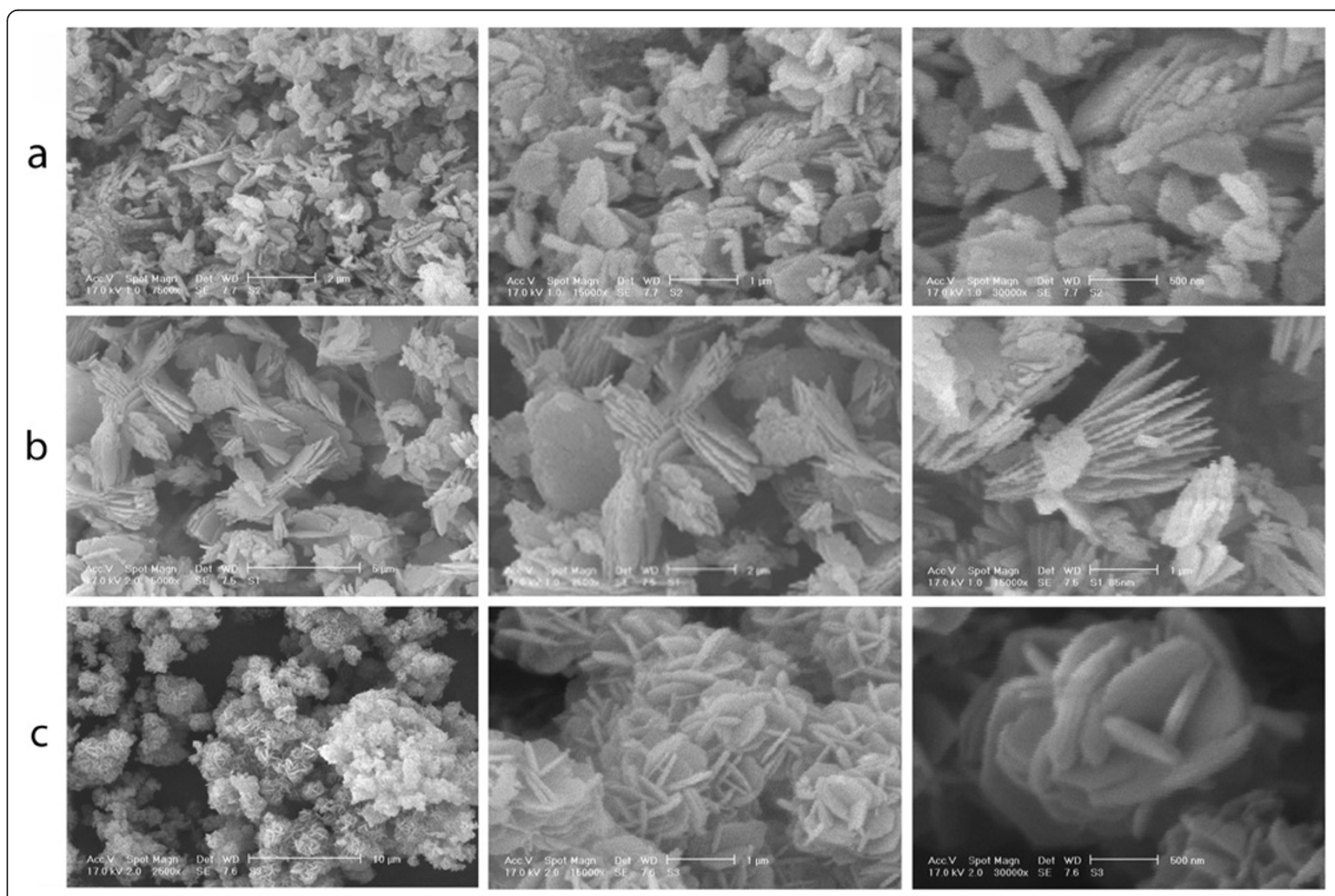

Figure 3 The SEM images of the synthesized $\mathrm{Li}_{2} \mathrm{SiO}_{3}$ nanomaterials obtained after different times at $180^{\circ} \mathrm{C}$. (a) 48 , (b) 72 , and (c) $96 \mathrm{~h}$. 


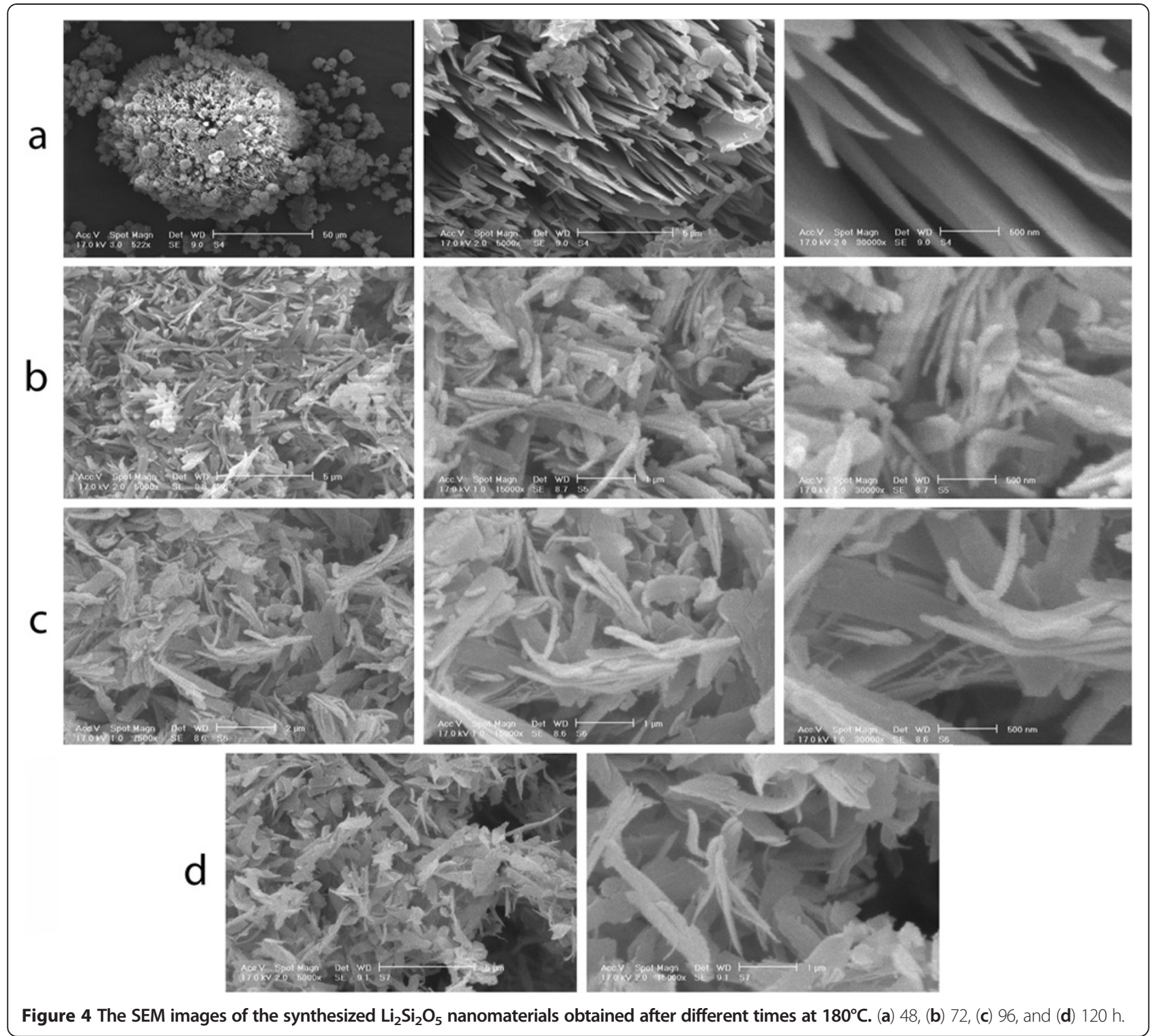

the emission spectrum of the synthesized $\mathrm{Li}_{2} \mathrm{SiO}_{3}$ nanomaterials, an intense peak appears at $410.03 \mathrm{~nm}$. In comparison, an intense peak at $291.45 \mathrm{~nm}$ is observed in the emission spectrum of the synthesized $\mathrm{Li}_{2} \mathrm{Si}_{2} \mathrm{O}_{5}$ nanomaterials. With increasing in the reaction time, no shift is observed in the emission spectrum of the obtained $\mathrm{Li}_{2} \mathrm{SiO}_{3}$ and $\mathrm{Li}_{2} \mathrm{Si}_{2} \mathrm{O}_{5}$ nanomaterials. However, increasing band intensities in the emission spectra of both compounds are observed with increasing reaction time.

\section{Structural optimization}

The crystal structure and locations of the atoms of the $\mathrm{Li}_{2} \mathrm{SiO}_{3}$ [45] and $\mathrm{Li}_{2} \mathrm{Si}_{2} \mathrm{O}_{5}$ [36] determined from X-ray diffraction data are used as a starting point for total energy minimization. The optimized unit cells of the $\mathrm{Li}_{2} \mathrm{SiO}_{3}$ and $\mathrm{Li}_{2} \mathrm{Si}_{2} \mathrm{O}_{5}$ are shown in Figures 3 and 4 , respectively.
Optimization (relaxation) of the atomic positions and crystal cell parameters was performed before the main calculations of the electronic characteristics, total electronic energy, band energy dispersion, density of electronic states, and optical properties.

\section{Electronic structures}

The calculated band structure of the compounds along high symmetry points of the first Brillouin zone is plotted in Figure 7 , where the labeled $k$ points are present as $\mathrm{G}(0.000,0.000,0.000), \mathrm{Z}(0.000,0.000,0.500)$, $\mathrm{T}(-0.500,0.500,0.500), \mathrm{Y}(-0.500,0.500,0.000), \mathrm{S}(0.000$, $0.500,0.000)$, and $\mathrm{R}(0.000,0.500,0.500)$ for $\mathrm{Li}_{2} \mathrm{SiO}_{3}$; and $\mathrm{G}(0.000,0.000,0.000), \mathrm{Z}(0.000,0.000,0.500), \mathrm{T}(-0.500$, $0.000,0.500), Y(-0.500,0.000,0.000), S(-0.500,0.500$, $0.000), X(0.000,0.500,0.000), U(0.000,0.500,0.500)$, and 


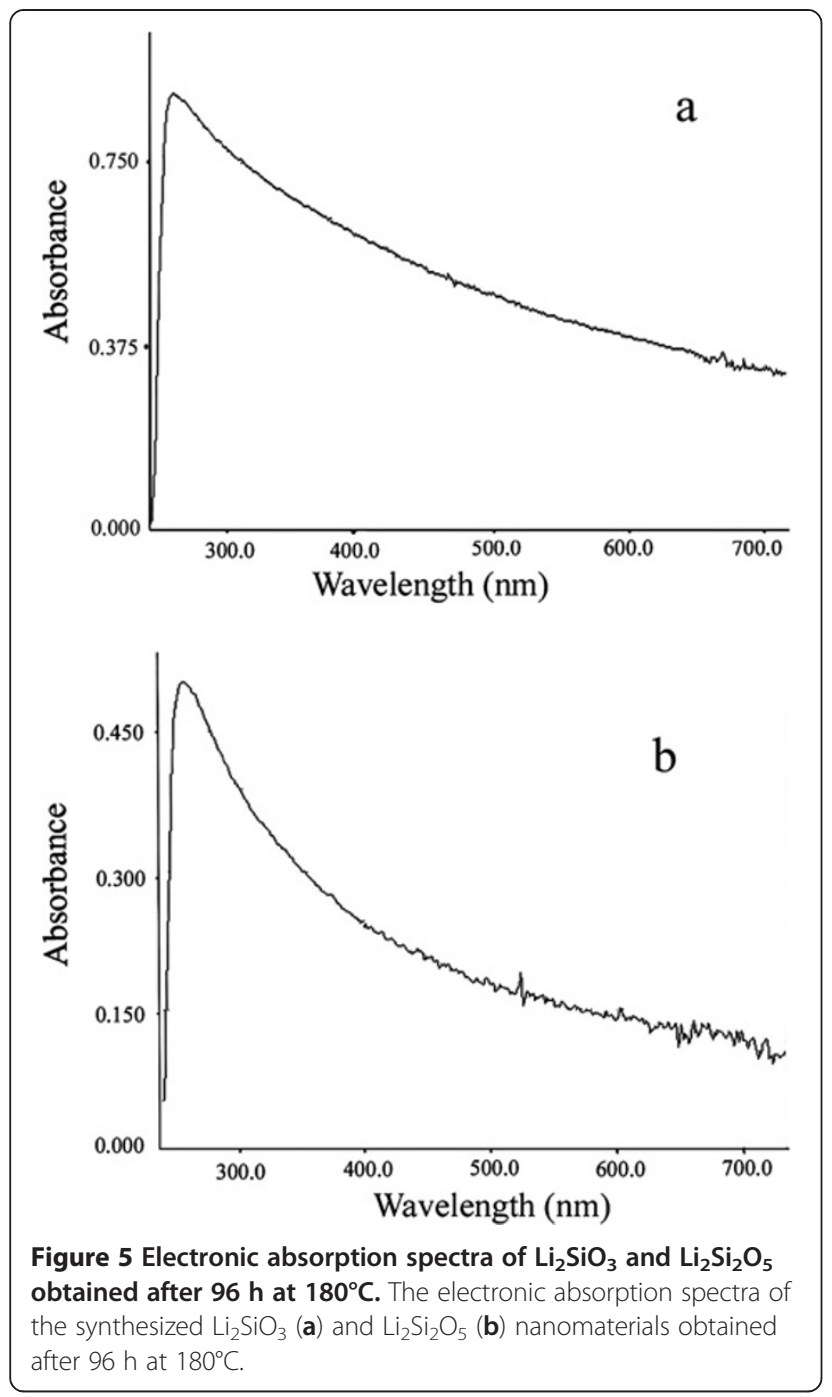

$\mathrm{R}(-0.500,0.500,0.500)$ for $\mathrm{Li}_{2} \mathrm{Si}_{2} \mathrm{O}_{5}$. It is found that the top of the valence bands (VBs) has a small dispersion, whereas the bottom of the conduction bands (CBs) has a big dispersion for both $\mathrm{Li}_{2} \mathrm{SiO}_{3}$ and $\mathrm{Li}_{2} \mathrm{Si}_{2} \mathrm{O}_{5}$. The lowest energy $(4.575 \mathrm{eV})$ of the conduction bands (CBs) of $\mathrm{Li}_{2} \mathrm{SiO}_{3}$ is localized at the $\mathrm{G}$ point, and the highest energy $(0.00 \mathrm{eV})$ of VBs is localized at the $\mathrm{Z}$ point. In the case of the $\mathrm{Li}_{2} \mathrm{Si}_{2} \mathrm{O}_{5}$, the lowest energy $(4.776 \mathrm{eV})$ of the conduction bands (CBs) is localized at the $\mathrm{G}$ point, and the highest energy $(0.00 \mathrm{eV})$ of VBs is localized at the $\mathrm{X}$ point.

To our knowledge, the optical band gap of the bulk $\mathrm{Li}_{2} \mathrm{SiO}_{3}$ and $\mathrm{Li}_{2} \mathrm{Si}_{2} \mathrm{O}_{5}$ has not been measured. It is well known that both local-density approximation and GGA density functional theory calculations systematically underestimate the band gap of insulators and semiconductors [1]. On the other hand, nanomaterials, compared to the corresponding bulk materials, have wider band gap and therefore show a blue shift in the electronic absorption and
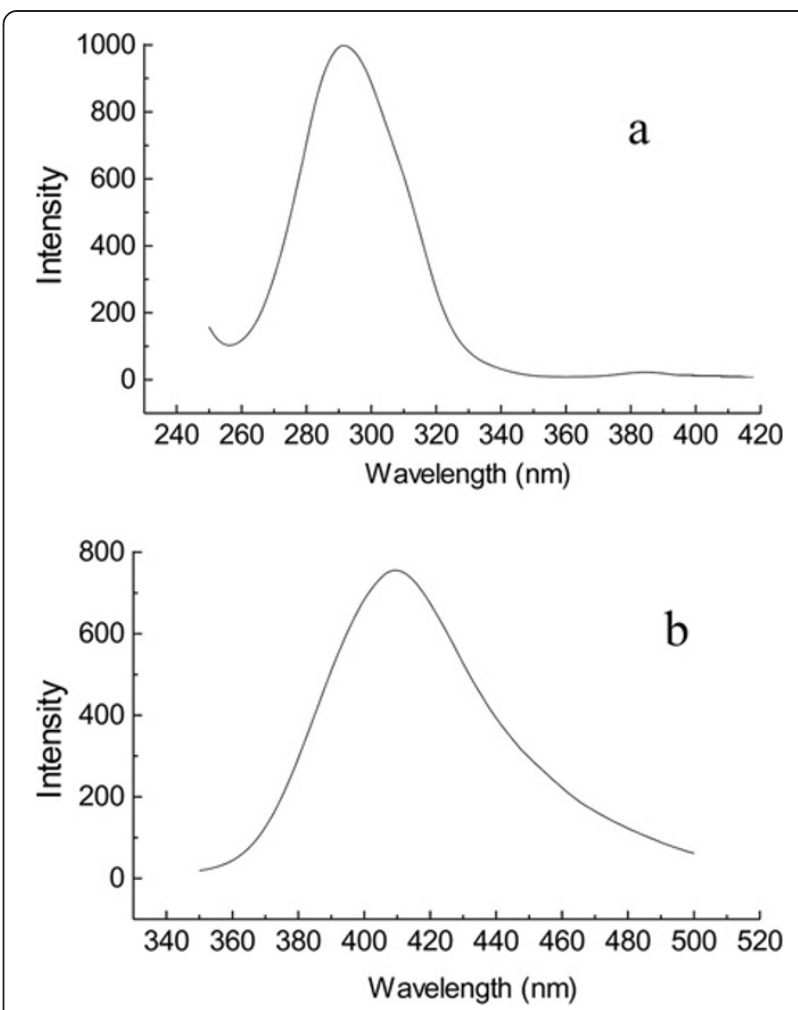

Figure 6 Emission spectra of $\mathrm{Li}_{2} \mathrm{SiO}_{3}$ and $\mathrm{Li}_{2} \mathrm{Si}_{2} \mathrm{O}_{5}$ obtained after $96 \mathrm{~h}$ at $180^{\circ} \mathrm{C}$. The emission spectra of the synthesized $\mathrm{Li}_{2} \mathrm{SiO}_{3}(\mathbf{a})$ and $\mathrm{Li}_{2} \mathrm{Si}_{2} \mathrm{O}_{5}(\mathbf{b})$ nanomaterials obtained after $96 \mathrm{~h}$ at $180^{\circ} \mathrm{C}$.

photoluminescence spectra [46,47]. In the orthogonalized linear combination of atomic orbital calculations, the band gap of $\mathrm{Li}_{2} \mathrm{SiO}_{3}$ and $\mathrm{Li}_{2} \mathrm{Si}_{2} \mathrm{O}_{5}$ was found to be 7.26 and $7.45 \mathrm{eV}$ respectively [48]. Also, a band gap of $5.7 \mathrm{eV}$ [1] and $5.36 \mathrm{eV}$ [49] for $\mathrm{Li}_{2} \mathrm{SiO}_{3}$ and $5.5 \mathrm{eV}$ [1] for $\mathrm{Li}_{2} \mathrm{Si}_{2} \mathrm{O}_{5}$ is predicted by DFT calculations using the GGA within Perdew and Wang (PW91) scheme. However, according to our calculations, the values of the calculated band gap for $\mathrm{Li}_{2} \mathrm{SiO}_{3}$ and $\mathrm{Li}_{2} \mathrm{Si}_{2} \mathrm{O}_{5}$ are 4.575 and $4.776 \mathrm{eV}$ respectively, which are comparable with the experimental values (4.49 and $4.56 \mathrm{eV}$ obtained for $\mathrm{Li}_{2} \mathrm{SiO}_{3}$ and $\mathrm{Li}_{2} \mathrm{Si}_{2} \mathrm{O}_{5}$ nanomaterials obtained after $96 \mathrm{~h}$ at $180^{\circ} \mathrm{C}$ ) measured from the electronic absorption spectrum of the synthesized nanomaterials.

The total density of states and partial densities of states for $\mathrm{Li}_{2} \mathrm{SiO}_{3}$ and $\mathrm{Li}_{2} \mathrm{Si}_{2} \mathrm{O}_{5}$ are shown in Figures 8 and 9 respectively. The $\mathrm{VBs}$ at -19.42 to $-15.00 \mathrm{eV}$ for $\mathrm{Li}_{2} \mathrm{SiO}_{3}$ and at -19.61 to $-15.00 \mathrm{eV}$ for $\mathrm{Li}_{2} \mathrm{Si}_{2} \mathrm{O}_{5}$ have significant contributions from O- $2 s$ states; however, small contributions from $\mathrm{Si}-3 s, 3 p$ and $\mathrm{Li}-2 s, \mathrm{O}-2 p$ states still can be observed at these energy intervals.

The most complex VBs are from $-8.07 \mathrm{eV}$ in $\mathrm{Li}_{2} \mathrm{SiO}_{3}$ and $-8.84 \mathrm{eV}$ in $\mathrm{Li}_{2} \mathrm{Si}_{2} \mathrm{O}_{5}$ to the Fermi level $(0.0 \mathrm{eV})$. According to the partial density of states, it is confirmed 

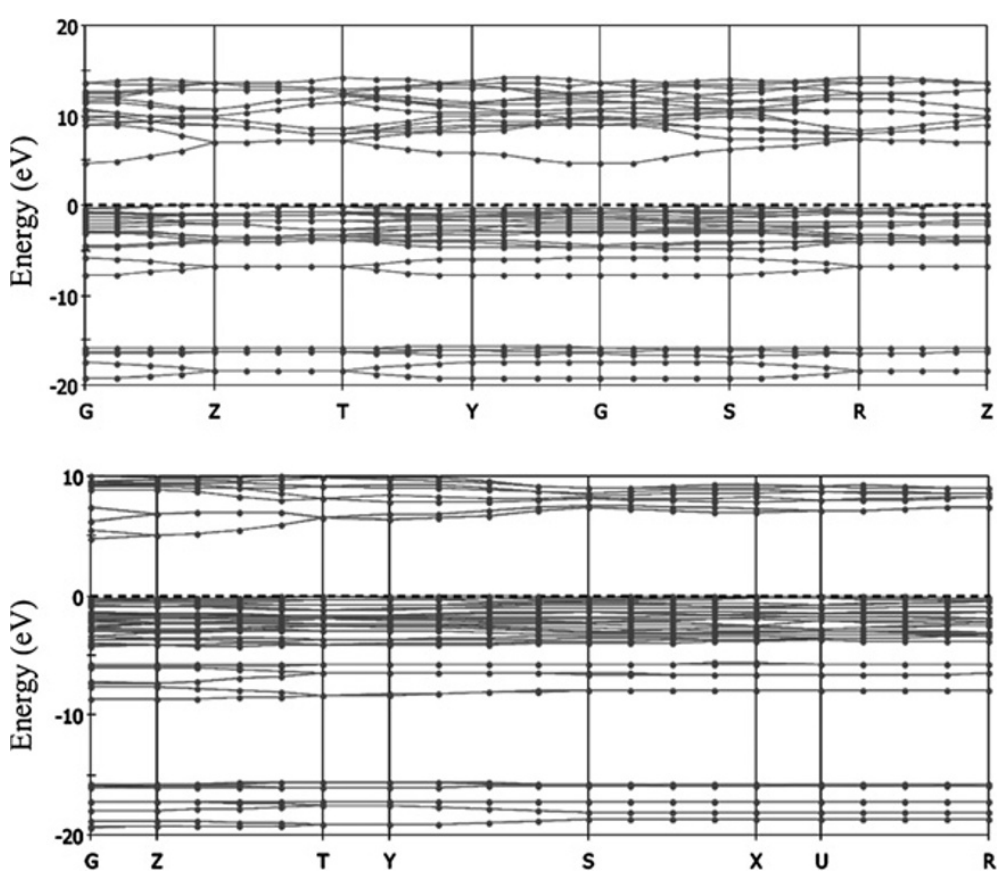

Figure 7 Calculated band structures of $\mathrm{Li}_{2} \mathrm{SiO}_{3}$ (top) $\mathrm{Li}_{2} \mathrm{Si}_{2} \mathrm{O}_{5}$ (bottom).

that the valence bands at these energy intervals are essentially formed by $\mathrm{O}-2 p$ for both compounds, along with small admixture $\mathrm{Li}-2 s$, while the contributions from $\mathrm{Si}-3 s, 3 p$ states in $\mathrm{Li}_{2} \mathrm{Si}_{2} \mathrm{O}_{5}$ are significant and cannot be neglected. Such characteristic indicates that covalent bonds could be formed among $\mathrm{O}-2 p$ and $\mathrm{Si}-3$ $p, 3 s$ states in $\mathrm{Li}_{2} \mathrm{Si}_{2} \mathrm{O}_{5}$. However, in the case of $\mathrm{Li}_{2} \mathrm{SiO}_{3}$, these contributions are weaker. The valence bands at these energy ranges can be further divided into two parts. Such a splitting characteristic of valence bands reflects different bonding behaviors. The first parts located at -8.84 to $-5.19 \mathrm{eV}$ (for $\mathrm{Li}_{2} \mathrm{SiO}_{3}$ ) and -8.07 to $-4.62 \mathrm{eV}$ (for $\mathrm{Li}_{2} \mathrm{Si}_{2} \mathrm{O}_{5}$ ) are due to the bonding between $\mathrm{Si}-3 s, 3 p, \mathrm{Li}-2 s$ orbits and $\mathrm{O}-2 p$ orbits, while the second part from -5.19 to $-4.62 \mathrm{eV}$ for $\mathrm{Li}_{2} \mathrm{SiO}_{3}$ and $\mathrm{Li}_{2} \mathrm{Si}_{2} \mathrm{O}_{5}$, respectively, to the Fermi level $(0.0 \mathrm{eV})$ indicates the small interaction between $\mathrm{Si}-3 p, \mathrm{Li}-2 s$ orbits and $\mathrm{O}-2 p$ orbits. Analyzing the PDOS also suggests ionic interactions between $\mathrm{Si}-2 s$, $2 p$ orbits and $\mathrm{O}-2 s, 2 p$ orbits.

The conduction bands between 4.23 and $14.61 \mathrm{eV}$ for $\mathrm{Li}_{2} \mathrm{SiO}_{3}$ come from Si-3 $s, 3 p$ states, Li- $2 s$ states, and $\mathrm{O}-3 s, 3 p$ states. In comparison, the bands between 4.23 and $10.00 \mathrm{eV}$ for $\mathrm{Li}_{2} \mathrm{Si}_{2} \mathrm{O}_{5}$ come primarily from $\mathrm{Si}-3 p$ states, with small contribution from $\mathrm{Si}-3 s$ states, Li- $2 s$ states, and $\mathrm{O}-2 s, 2 p$ states. The hybridization between $\mathrm{Si}-3 s, 3 p$ orbits and $\mathrm{O}-2 s, 2 p$ orbits at upper valence bands is the important structural character of the two compounds.

\section{Optical properties}

The optical properties can be gained from the complex dielectric function $[50,51]$ :

$$
\varepsilon(\omega)=\varepsilon_{1}(\omega)+i \varepsilon_{2}(\omega) .
$$

This is mainly connected with the electronic structures and characterizes the linear response of the material to an electromagnetic radiation, and therefore governs the propagation behavior of radiation in a medium. The imaginary part of the dielectric function $\varepsilon_{2}(\omega)$ represents the optical absorption in the crystal, which can be calculated from the electronic structure through the joint density of states and the momentum matrix elements between the occupied and the unoccupied wave functions within the selection rules and is given

$$
\check{a}_{2}=\frac{2 e^{2} \circlearrowright}{\grave{U}^{\circ}} \sum_{k, v, c}\left|\left\langle\emptyset_{k}^{c}|\hat{u} \times r| \varnothing_{k}^{V}\right\rangle\right|^{2} \ddot{a}\left[\left(E_{k}^{c}-E_{k}^{v}\right)-E\right],
$$

where $e$ is the electronic charge, and $\phi_{k}^{c}$ and $\phi_{k}^{\mathrm{v}}$ are the conduction band and valence band wavefunctions at $k$, respectively.

The real part $\varepsilon_{1}(\omega)$ is evaluated from the imaginary part $\varepsilon_{2}(\omega)$ by the Kramers-Kronig transformation. The other optical constants such as the refractive index $n(\omega)$, extinction coefficient $k(\omega)$, optical reflectivity $R(\omega)$ absorption coefficient $\alpha(\omega)$, energy loss spectrum $L(\omega)$, and the complex 

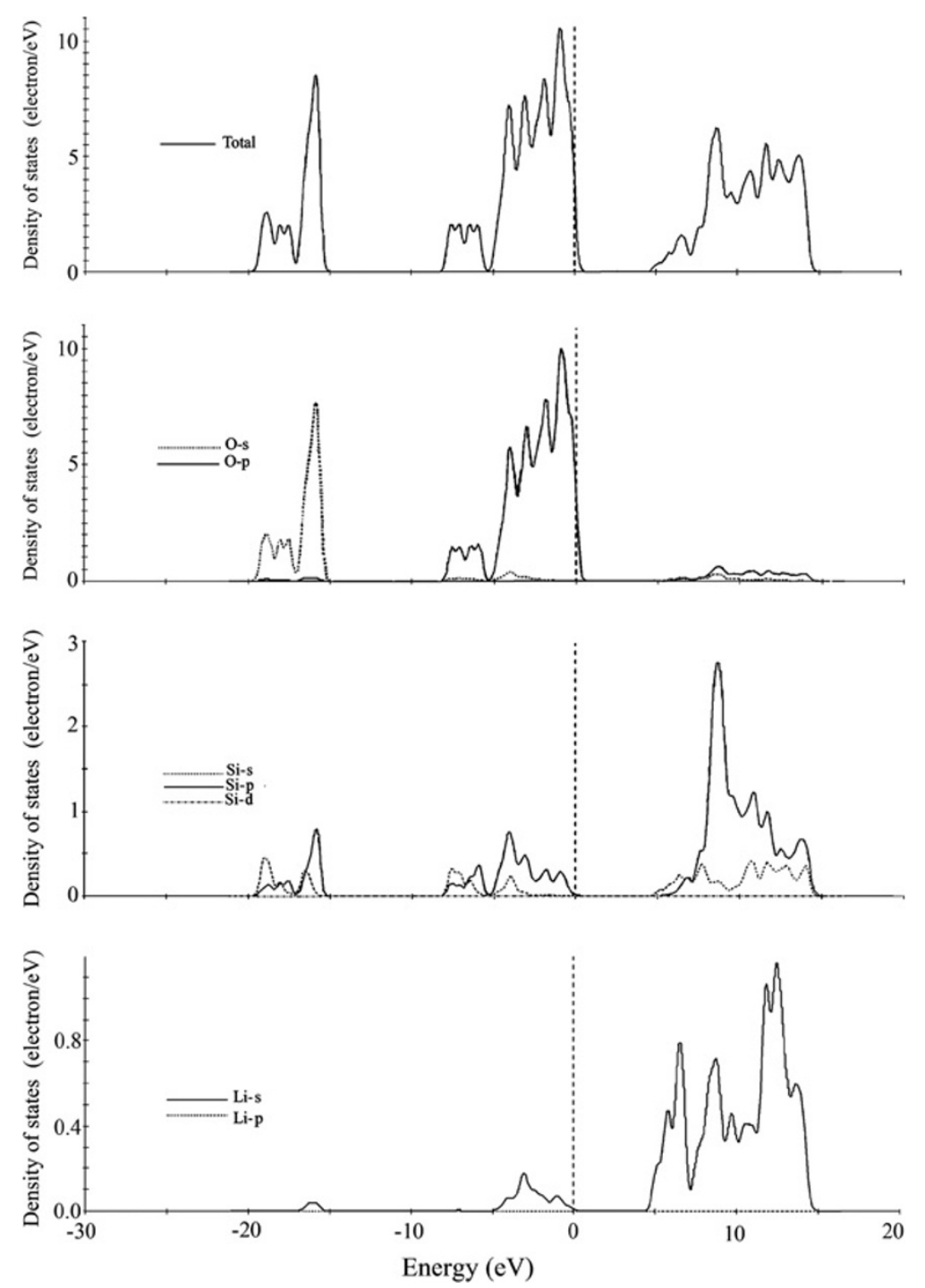

Figure 8 Total and partial densities of states for $\mathrm{Li}_{2} \mathrm{SiO}_{3}$. The position of the Fermi level is set at $0.0 \mathrm{eV}$.

conductivity function $\sigma(\omega)$ can be computed from the complex dielectric function $\varepsilon_{1}(\omega)$, through the following relations $[49,50]$ :

$$
\begin{aligned}
n(\grave{u}) & =\sqrt{|\grave{a}(\grave{u})|+\grave{a}_{1}}(\grave{u}) / 2 \\
k(\grave{u}) & =\sqrt{\left(|\grave{a}(\grave{u})|-\stackrel{\circ}{1}_{1}(\grave{u}) / 2\right)} \\
R(\grave{u}) & =\frac{(n-1)^{2}+k^{2}}{(n-1)^{2}+k^{2}} \\
\dot{a}(\grave{u}) & =2 k \grave{u} / \mathrm{c} \\
L(\grave{u}) & =\operatorname{Im}\left(\frac{-1}{\grave{a}(\grave{u})}\right)=\frac{\grave{a}_{2}(\grave{u})}{\grave{a}_{1}^{2}(\grave{u})+\grave{a}_{2}^{2}(\grave{u})}
\end{aligned}
$$

$$
\dot{o}(\grave{u})=\dot{o}^{1(\grave{u})}+\mathrm{i} \dot{o}^{2(\grave{u})}=-\mathrm{i} \frac{\grave{u}}{4 ð}[\grave{a}(\grave{u})-1]
$$

The dielectric functions of $\mathrm{Li}_{2} \mathrm{SiO}_{3}$ and $\mathrm{Li}_{2} \mathrm{Si}_{2} \mathrm{O}_{5}$ were calculated based on the electronic structure. The $\varepsilon_{1}(\omega)$ and $\varepsilon_{2}(\omega)$ as a function of the photon energy are shown in Figure 10 for $\mathrm{Li}_{2} \mathrm{SiO}_{3}$ and $\mathrm{Li}_{2} \mathrm{Si}_{2} \mathrm{O}_{5}$.

The imaginary part of $\varepsilon(\omega)$ in $\mathrm{Li}_{2} \mathrm{SiO}_{3}$ has three intense bands located at 9.02, 11.11, and $14.35 \mathrm{eV}$. The first peak corresponds mainly to the transition from $\mathrm{O}-2 p$ states (VBs) to the empty $\mathrm{Li}-2 s$ and $\mathrm{Si}-3 s$ states (CBs) above the Fermi level. The second and third peaks are mainly due to the transitions from $\mathrm{O}-2 p$ states (VBs) to the $\mathrm{Si}-3 p$ and $\mathrm{Li}-2 s$ states (CBs) above the Fermi level. In contrast, $\mathrm{Li}_{2} \mathrm{Si}_{2} \mathrm{O}_{5}$ has a prominent absorption peak, located at the photon energies of $9 \mathrm{eV}$ and two weaker bands located at 

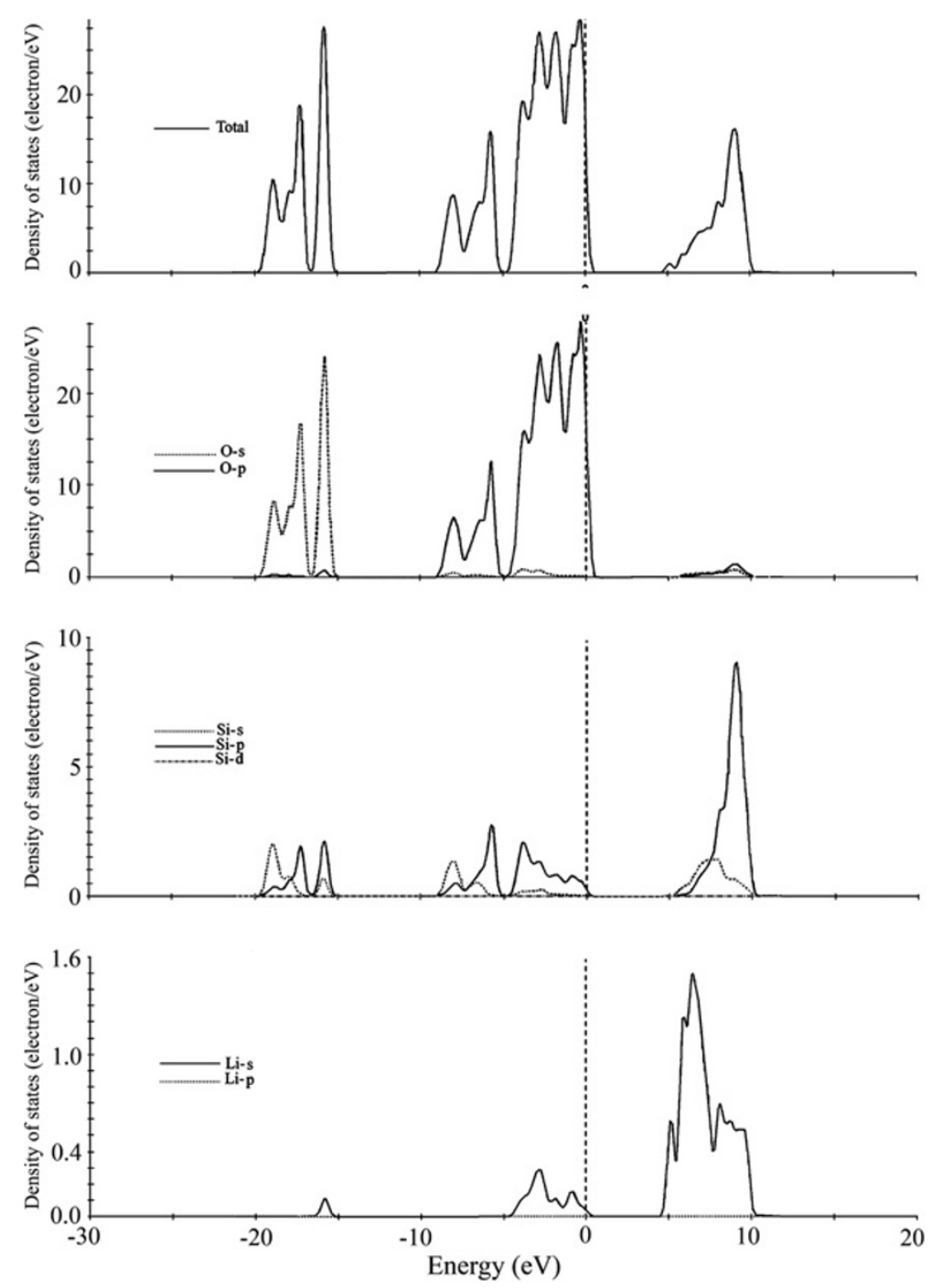

Figure 9 Total and partial densities of states for $\mathrm{Li}_{2} \mathrm{Si}_{2} \mathrm{O}_{5}$. The position of the Fermi level is set at $0.0 \mathrm{eV}$.

11.74 and $15 \mathrm{eV}$. The main peak at the $9 \mathrm{eV}$ is due to strong interband transitions between the $\mathrm{O}-2 p$ states (VBs) and $\mathrm{Si}-3 p$ empty states (CBs). It is noted that a peak in $\varepsilon_{2}(\omega)$ does not correspond to a single interband transition since many direct or indirect transitions may be found in the band structure with an energy corresponding to the same peak [52]. The peak amplitudes of $\mathrm{Li}_{2} \mathrm{SiO}_{3}$ are larger than those of the $\mathrm{Li}_{2} \mathrm{Si}_{2} \mathrm{O}_{5}$ crystals, due to the fact that the band structures for the two compounds are not similar.

For the real part $\varepsilon_{1}(\omega)$ of the dielectric function $\varepsilon(\omega)$, the most important quantity is the 0 frequency limit $\varepsilon_{1}$ (0), which is the electronic part of the static dielectric constant and depends strongly on the band gap. A smaller energy gap yields a larger $\varepsilon_{1}(0)$ value. This could be explained on the basis of the Penn model [52]:

$$
\varepsilon_{1}(0) \approx 1+\left(h \omega_{p} / E_{g}\right)^{2} .
$$
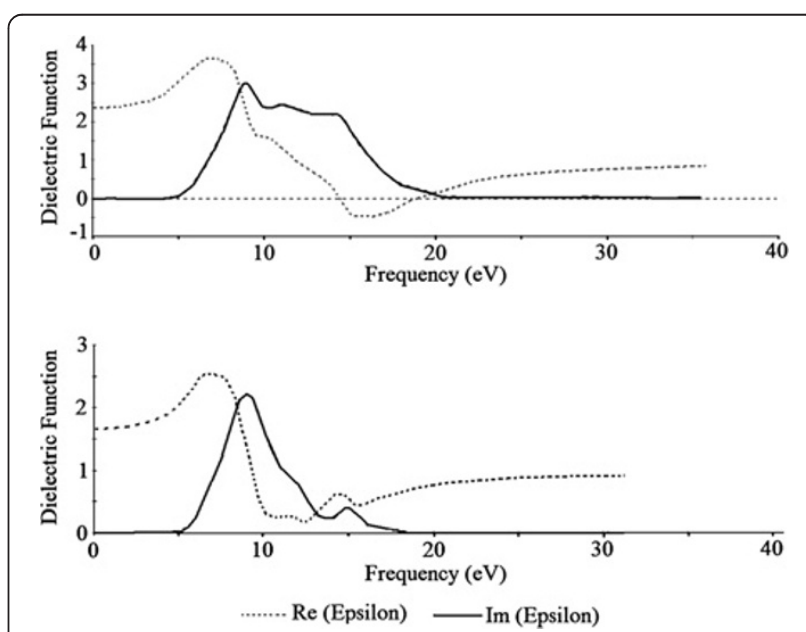

Figure 10 Dielectric functions of $\mathrm{Li}_{2} \mathrm{SiO}_{3}$ (top) $\mathrm{Li}_{2} \mathrm{Si}_{2} \mathrm{O}_{5}$ (bottom). 
The energy gap $\left(E_{\mathrm{g}}\right)$ could be determined from this expression by using the values of $\varepsilon_{1}(0)$ and the plasma energy $\mathrm{h} \omega_{\mathrm{p}}$. The calculated and experimental $E_{\mathrm{g}}$ and also the calculated static dielectric constants $\varepsilon_{1}(0)$ of $\mathrm{Li}_{2} \mathrm{SiO}_{3}$ and $\mathrm{Li}_{2} \mathrm{Si}_{2} \mathrm{O}_{5}$ are listed in Table 1 .

The calculated results on the absorption, reflectivity, and energy loss spectra by norm-conserving pseudo-potentials were shown in Figures 11, 12, 13. According to the absorption spectra, the absorption edges are located at $9.11,11.85$, and $14.70 \mathrm{eV}$ for lithium metasilicate and at $8.2,11.60$, and $15 \mathrm{eV}$ for lithium disilicate. The absorption coefficients decrease rapidly in the low-energy region, which is the representative character of the semiconductors and insulators.

The calculated reflectivity for lithium metasilicate at 0 to $5 \mathrm{eV}$ is lower than $10 \%$ and a maximum value of roughly $35.0 \%$ is calculated at about $17.53 \mathrm{eV}$. In comparison, the reflectivity for lithium disilicate at 0 to $5 \mathrm{eV}$ is calculated to be lower than $2 \%$. The calculated reflectivity spectrum of lithium disilicate shows a maximum value of about $15 \%$ at $9.9 \mathrm{eV}$. According to the absorption and reflectivity spectra, it is concluded that lithium metasilicate and lithium disilicate are transmitting for frequencies of $<4.00 \mathrm{eV}$.

The energy loss spectrum describes the energy loss of a fast electron traversing in the material [53]. The main peak is generally defined as the bulk plasma frequency [54]. At energies smaller than $5.0 \mathrm{eV}$, no distinct peak is calculated due to the fact that $\varepsilon_{2}(\omega)$ is still large at these energy values. The main peaks of energy loss spectra, as shown in Figure 13, are calculated at about 12.82 and $15.55 \mathrm{eV}$ for lithium disilicate and $19.5 \mathrm{eV}$ for lithium metasilicate. Such calculations may stimulate the experimental investigations.

\section{Conclusions}

This study describes the hydrothermal synthesis of highly crystalline and pure lithium metasilicate and lithium disilicate nanoparticles. The PXRD patterns indicate that the pure lithium metasilicate and lithium disilicate

Table 1 Theoretical and experimental energy gaps $\left(E_{\mathrm{g}}\right)$ and the calculated average static dielectric constant of $\mathrm{Li}_{2} \mathrm{SiO}_{3}$ and $\mathrm{Li}_{2} \mathrm{Si}_{2} \mathrm{O}_{5}$

\begin{tabular}{|c|c|c|c|c|}
\hline & \multicolumn{2}{|c|}{$\mathrm{Li}_{2} \mathrm{SiO}_{3}$} & \multicolumn{2}{|c|}{$\mathrm{Li}_{2} \mathrm{Si}_{2} \mathrm{O}_{5}$} \\
\hline & Calculated & Experimental & Calculated & Experimental \\
\hline $\begin{array}{l}\text { Pseudo- } \\
\text { potentials }\end{array}$ & $\begin{array}{c}\text { Norm- } \\
\text { conserving }\end{array}$ & - & $\begin{array}{c}\text { Norm- } \\
\text { conserving }\end{array}$ & - \\
\hline \multirow[t]{3}{*}{$E_{g}(\mathrm{eV})$} & 4.575 & $4.49(\mathrm{a})$ & 4.776 & $4.56(\mathrm{a})$ \\
\hline & & $4.51(b)$ & & $4.53(b)$ \\
\hline & & 4.51 (c) & & 4.48 (c) \\
\hline$\varepsilon_{1}(0)$ & 2.39 & - & 1.70 & - \\
\hline
\end{tabular}

The experimental $E_{\mathrm{g}}$ values calculated from the UV-vis spectra for the synthesized $\mathrm{Li}_{2} \mathrm{SiO}_{3}$ and $\mathrm{Li}_{2} \mathrm{Si}_{2} \mathrm{O}_{5}$ nanomaterials after (a) 48, (b) 72 and (c) $96 \mathrm{~h}$ at $180^{\circ} \mathrm{C}$.

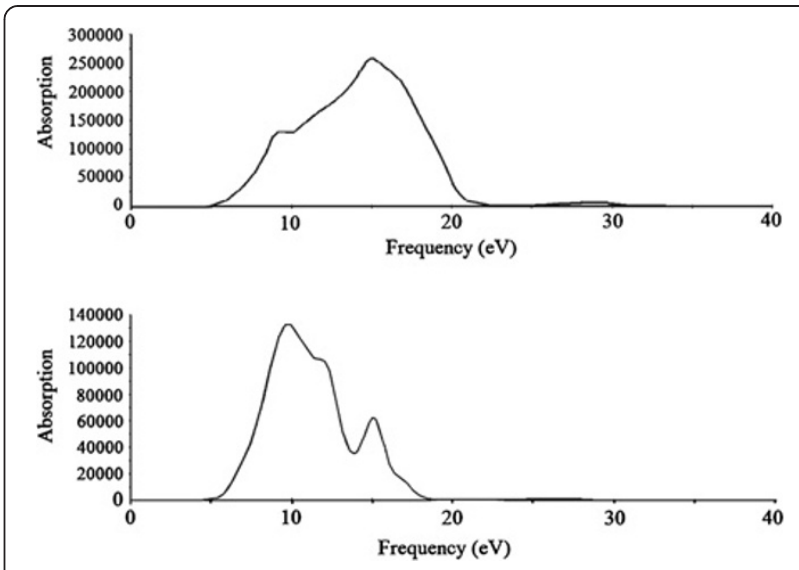

Figure 11 Calculated absorption spectra of $\mathrm{Li}_{2} \mathrm{SiO}_{3}$ (top) and $\mathrm{Li}_{2} \mathrm{Si}_{2} \mathrm{O}_{5}$ (bottom).

crystallized well under hydrothermal condition. SEM images show the reaction time effect on the morphology and homogeneity of the synthesized materials. The intensity of the bands in the emission spectra increases with increasing reaction time in both lithium metasilicate and lithium disilicate.

The electronic band structure along with DOS calculated by the DFT method indicates that $\mathrm{Li}_{2} \mathrm{SiO}_{3}$ and $\mathrm{Li}_{2} \mathrm{Si}_{2} \mathrm{O}_{5}$ have indirect energy band gaps of about 4.575 and $4.776 \mathrm{eV}$, respectively. The hybridized interactions between $\mathrm{Si}-3 s, 3 p$ orbits and $\mathrm{O}-2 p$ orbits are revealed as the important structural characteristics of the two compounds, which leads to large band gaps.

The optical properties, including the dielectric function, absorption coefficient, reflectivity and energy loss spectra, also have been calculated by DFT methods. According to the calculated absorption and reflectivity spectra, $\mathrm{Li}_{2} \mathrm{SiO}_{3}$ and $\mathrm{Li}_{2} \mathrm{Si}_{2} \mathrm{O}_{5}$ are theoretically transmitting for frequencies of $<4.00 \mathrm{eV}$. Therefore, $\mathrm{Li}_{2} \mathrm{SiO}_{3}$ and $\mathrm{Li}_{2} \mathrm{Si}_{2} \mathrm{O}_{5}$ are the excellent visible and IR transparent materials, which have been

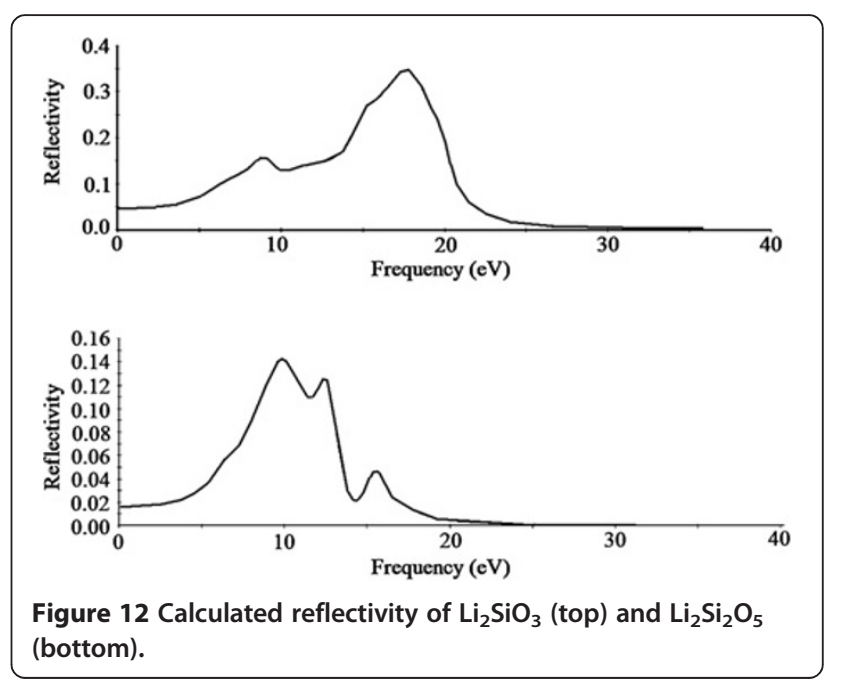




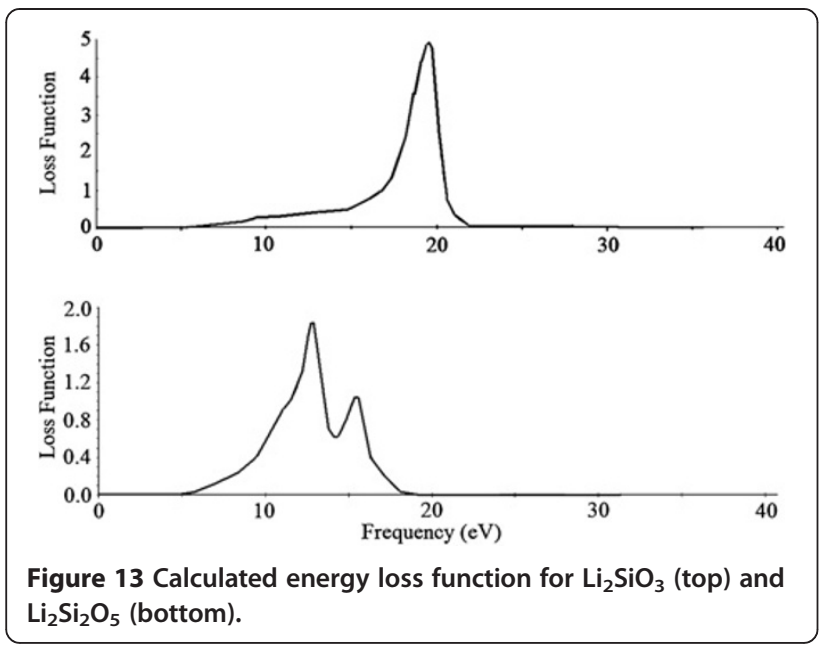

experimentally proved. Furthermore, for both compounds, the imaginary part $\varepsilon_{2}(\omega)$ of the dielectric function $\varepsilon(\omega)$ has been discussed in detail according to the band structure. It is found that the peak intensities in $\mathrm{Li}_{2} \mathrm{SiO}_{3}$ are obviously enhanced compared to that in $\mathrm{Li}_{2} \mathrm{Si}_{2} \mathrm{O}_{5}$.

\section{Competing interests}

The authors declare that they have no competing interest.

\section{Authors' contributions}

All authors, AA, SK, SWJ, MD, and AB, participated in the experiments and read and approved the final manuscript.

\section{Authors' information}

SK got his B.S. degree from the University of Birjand in the field of applied chemistry in 2007. He got his M.Sc. degree from the University of Tabriz in the field of inorganic chemistry in August 2010. He is now a Ph.D. student in faculty of chemistry at University of Semnan, Iran in the field of inorganic chemistry. AA got his B.S. and M.Sc. degree from the University of Tabriz, Iran in the field of chemistry in 1972 and 1974, respectively. He got his Ph.D. degree from the University of Paris, France in the field of inorganic chemistry in 1978. He is now a professor in inorganic chemistry at University of Tabriz, Iran. S.W. joo got his B.S. and M.S. degree from seoul national university in Feb. 1982 and 1984. He got his Ph.D. degree from the University of Michigan, Ann Arbor. From 1995 up to present he is the professor in the school of mechanical engineering, yeungnam University. MD got her B.S. and M.Sc. degree from the University of Tabriz, Iran in the field of chemistry and inorganic chemistry in 2004 and 2006, respectively. She got her Ph.D. degree from the University of Tabriz, Iran in the field of inorganic-solid state chemistry in 2010. She is now post doctorate student and associate professor in the research group of Prof. Rostami at School of Engineering Emerging Technologies, University of Tabriz, Iran and in the department of inorganic chemistry in University of Tabriz, Iran. AB got his B.S. and M.Sc. degree from the University of Tabriz, Iran and from the University of Urmia in the field of chemistry and inorganic chemistry in 2004 and 2006, respectively. He got his Ph.D. degree from University of Tabriz, Iran in the field of inorganic chemistry in 2010.

\section{Acknowledgment}

The authors express their sincere thanks to the authorities of Tabriz University for financing the project.

\section{Author details}

'Department of Inorganic Chemistry, Faculty of Chemistry, University of Tabriz, Tabriz, Iran. ${ }^{2}$ School of Mechanical Engineering WCU Nano Research Center, Yeungnam University, Gyeongsan 712-749, South Korea. ${ }^{3}$ Laboratory of Photonics and Nano Crystals, School of Engineering-Emerging
Technologies, University of Tabriz, Tabriz, Iran. ${ }^{4}$ Department of Chemistry, Payame Noor University, Tehran 19395-4697, Iran

Received: 6 October 2012 Accepted: 19 February 2013 Published: 12 March 2013

\section{References}

1. $\mathrm{Du}, \mathrm{J}$, Corrales, LR: Characterization of the structural and electronic properties of crystalline lithium silicates. J. Phys. Chem. 110, 22346 (2006)

2. Beall, GH: Design and Properties of Glass-Ceramics. Annu. Rev. Mater. Sci. 22, 91 (1992)

3. Vincent, CA: Lithium batteries: a 50-year perspective, 1959-2009. Solid State Ion. 134, 159 (2000)

4. Lu, CH, Cheng, LW: Reaction mechanism and kinetics analysis of lithium nickel oxide during solid-state reaction. J. Mater. Chem. 10, 1403 (2000)

5. Broussely, M, Perton, F, Biensan, P, Bodet, JM, Labat, J, Lecerf, A, Delmas, C, Rougier, A, Peres, JP: $\mathrm{Li}_{x} \mathrm{NiO}_{2}$, a promising cathode for rechargeable lithium batteries. J. Power. Source. 54, 109 (1995)

6. Subramanian, V, Chen, CL, Chou, HS, Fey, GTK: Microwave-assisted solidstate synthesis of $\mathrm{LiCOO}_{2}$ and its electrochemical properties as a cathode material for lithium batteries. J. Mater. Chem. 11, 3348 (2001)

7. Yang, $\mathrm{X}$, Tang, W, Kanoh, H, Ooi, K: Synthesis of lithium manganese oxide in different lithium-containing fluxes. J. Mater. Chem. 9, 2683 (1999)

8. Kudo, H, Okuno, K, Ohira, S: Tritium release behavior of ceramic breeder candidates for fusion reactors. J. Nucl. Mater. 155, 524 (1988)

9. Pfeiffer, $\mathrm{H}$, Bosch, $\mathrm{P}$, Bulbulian, $\mathrm{S}$ : Sol-gel synthesis of $\mathrm{Li}_{2} \mathrm{ZrSi}_{6} \mathrm{O}_{15}$ powders. J. Mater. Chem. 10, 1255 (2000)

10. Pfeiffer, $\mathrm{H}, \mathrm{Bosch}, \mathrm{P}$ : Thermal stability and high-temperature carbon dioxide sorption on hexa-lithium zirconate $\left(\mathrm{Li}_{6} \mathrm{Zr}_{2} \mathrm{O}_{7}\right)$. Chem. Mater. 17, 1704 (2005)

11. Mosqueda, HA, Vazquez, C, Bosch, P, Pfeiffer, H: Nanoscale domain control in multiferroic $\mathrm{BiFeO}_{3}$ thin films. Chem. Mater. 18, 2307 (2006)

12. Pfeiffer, $\mathrm{H}$, Vazquez, $\mathrm{C}, \mathrm{Lara}, \mathrm{VH}$, Bosch, $\mathrm{P}$ : Thermal behavior and $\mathrm{CO}_{2}$ absorption of $\mathrm{Li}_{2-x} \mathrm{Na}_{x} \mathrm{ZrO}_{3}$ solid solutions. Chem. Mater. 19, 922 (2007)

13. Vinod, MP, Bahnemann, D: Materials for all-solid-state thin-film rechargeable lithium batteries by sol-gel processing. J. Solid State Electrochem. 7, 498 (2002)

14. Zhang, B, Easteal, AJ: Effect of HNO3 on crystalline phase evolution in lithium silicate powders prepared by sol-gel processes. J. Mat. Sci. 43, 5139 (2008)

15. Cruz, D, Bulbulian, S, Lima, E, Pfeiffer, H: Kinetic analysis of the thermal stability of lithium silicates $\left(\mathrm{Li}_{4} \mathrm{SiO}_{4}\right.$ and $\left.\mathrm{Li}_{2} \mathrm{SiO}_{3}\right)$.J. Solid State Chem. 179, 909 (2006)

16. Nakazawa, T, Yokoyama, $\mathrm{K}$, Noda, $\mathrm{K}: \mathrm{Ab}$ initio $\mathrm{MO}$ study on hydrogen release from surface of lithium silicate. J. Nucl. Mat. 258, 571 (1998)

17. Munakata, K, Yokoyama, Y: Ab initio study of electron state in Li4Sio4 crystal. J. Nucl. Sci. Technol. 38, 915 (2001)

18. Taddia, M, Modesti, P, Albertazzi, A: Determination of macro-constituents in lithium zirconate for tritium-breeding applications. J. Nucl. Mat. 336, 173 (2005)

19. Pfeiffer, H, Bosch, P, Bulbulian, S: Synthesis of lithium silicates. J. Nucl. Mat. 257, 309 (1998)

20. van der Laan, JG, Kawamura, H, Roux, N, Yamaki, D: Ceramic breeder research and development: progress and focus. J. Nucl. Mat. 283, 99 (2000)

21. Cruz, D, Bulbulian, S: Synthesis of Li4SiO4 by a modified combustion method. J. Am. Ceram. Soc. 88, 1720 (2005)

22. Khomane, RB, Sharma, BK, Saha, S, Kulkarni, BD: Reverse microemulsion mediated sol-gel synthesis of lithium silicate nanoparticles under ambient conditions: scope for $\mathrm{CO}_{2}$ sequestration. Chem. Eng. Sci. 61, 3415 (2006)

23. Simoes, AZ, Moura, F, Onofre, TB, Ramirez, MA, Varela, JA, Longo, E: Microwave-hydrothermal synthesis of barium strontium titanate nanoparticles. J. Alloy Comp. 508, 620 (2010)

24. Alemi, A, Khademinia, S, Dolatyari, M, Bakhtiari, A: Hydrothermal synthesis, characterization, and investigation of optical properties of $\mathrm{Sb}^{3+}$-doped lithium silicates nanostructures. Int. Nano Lett. 2, 20 (2012)

25. Clark, SJ, Segall, MD, Pickard, CJ, Hasnip, PJ, Probert, MJ, Refson, K, Payne, MC: Materials Studio CASTEP, version 5.0. Accelrys, San Diego (2009)

26. Clark, SJ, Segall, MD, Pickard, CJ, Hasnip, PJ, Probert, MJ, Refson, K, Payne, MC: First principles methods using CASTEP. J. Kristallography 220, 567 (2005)

27. Hamann, DR, Schluter, M, Chiang, C: Norm-conserving pseudo-potentials. Phys. Rev. Lett. 43, 1494 (1979)

28. Monkhorst, $\mathrm{HJ}$, Furthmuller, J: Special points for Brillouin-zone integrations. Phys. Rev. B. 13, 5188 (1976)

29. Kalinkin, AM, Kalinkina, EV, Zalkind, OA, Makarova, TI: Mechanochemical interaction of alkali metal metasilicates with carbon dioxide: 2 . The 
influence of thermal treatment on the properties of activated samples. J. Colloid 70, 42 (2008)

30. Beneke, $\mathrm{K}$, Thiesen, P, Lagaly, G: Synthesis and properties of the sodium lithium silicate silinaite. Inorg. Chem. 34, 900 (1995)

31. Gutierrez, GM, Cruz, D, Pfeiffer, H, Bulbulian, S: Low temperature synthesis of Li2SiO3: effect on its morphological and textural properties. Res. Lett. Mat. Sci. 2, 1 (2008)

32. Zhang, B, Allan, TW, Easteal, J: Effect of HNO3 on crystalline phase evolution in lithium silicate powders prepared by sol-gel processes. J. Mat. Sci. 43, 5139 (2008)

33. Fuss, T, Mogus, A, Milankovic, B, Ray, CS, Lesher, CE, Youngman, R, Day, DE: Ex situ XRD, TEM, IR, Raman and NMR spectroscopy of crystallization of lithium disilicate glass at high pressure. J. Non-Cryst. Solids 352, 4101 (2006)

34. Soares, PC, Zanotto, ED, Fokin, VM, Jain, H: TEM and XRD study of early crystallization of lithium disilicate glasses. J. Non-Cryst. Solids 331, 217 (2003)

35. Zheng, $\mathrm{X}$, Wen, $\mathrm{G}$, Song, $\mathrm{L}$, Huang, $\mathrm{XX}$ : Effects of $\mathrm{P}_{2} \mathrm{O}_{5}$ and heat treatment on crystallization and microstructure in lithium disilicate glass ceramics. Acta Mat. 56, 549 (2008)

36. Smith, Rl, Howie, RA, West, AR, Pina, AA, Villafuerte-Castrejón, ME: Hydrogen bonding in barium hydroxide trihydrate by neutron diffraction. Acta Crystal. Sect. C. 46, 363 (1990)

37. Smith, Rl, West, AR, Abrahams, I, Bruce, PG: Rietveld structure refinement of metastable lithium disilicate using synchrotron X-ray powder diffraction data from the Daresbury SRS 8.3 diffractometer. Powder Diffraction. 5, 137 (1990)

38. Dejong, BHWS, Supér, HTJ, Spek, AL, Veldman, N, Nachtegaal, G, Fischer, JC: Mixed alkali systems: structure and ${ }^{29} \mathrm{Si}^{\mathrm{MASNMR}}$ of $\mathrm{Li}_{2} \mathrm{Si}_{2} \mathrm{O}_{5}$ and $\mathrm{K}_{2} \mathrm{Si}_{2} \mathrm{O}_{5}$. Acta Crystal. Sect. B. 54, 568 (1998)

39. Zanotto, ED: Metastable phases in lithium disilicate glasses. J. Non-Cryst. Solids 219, 42 (1997)

40. Liebau, F: Untersuchungen an Schichtsilikaten des Formeltyps $A_{m}\left(\mathrm{Si}_{2} \mathrm{O}_{5}\right)_{\text {n. I. }}$. Die Kristallstruktur der Zimmertemperaturform des $\mathrm{Li}_{2} \mathrm{Si}_{2} \mathrm{O}_{5}$. Acta Crystal. 14, 389 (1961)

41. Rindome, GE: Color-centers formed in glass by solar radiation. J. Am. Ceram. Soc. 45,7 (1962)

42. Engel, $\mathrm{K}$, Frischat, $\mathrm{G}$, Textures, $\mathrm{H}$ : Texture formation in a glass ceramic of $\mathrm{Li}_{2} \mathrm{O} 2 \mathrm{SiO}_{2}$ composition. Microstructures. 24, 155 (1995)

43. Deubener, J: Spectroscopy and thermal properties of $\mathrm{Ga}_{2} \mathrm{~S}_{3}$ based glasses. J. Non-Cryst. Solids 274, 195 (2000)

44. Paszkowicz, W, Wolska, A, Klepka, MT, All, SAE, Eldin, FME: Combined $X$-ray diffraction and absorption study of crystalline vanadium-doped lithium disilicate. Acta Phy. Pol.: A 117, 315 (2010)

45. Hesse, KF: Refinement of the crystal structure of lithium polysilicate. Acta Crystal. Sect. B. 33, 901 (1977)

46. Vollath, D: Nanomaterials: an Introduction to Synthesis. Properties and Applications, Wiley, Weinheim (2008)

47. Schaefer, HE: Nanoscience: the Science of the Small in Physics. Engineering, Chemistry, Biology and Medicine, Springer, Berlin (2010)

48. Ching, WY, Li, YP, Veal, BW, Lam, D: Electronic structures of lithium metasilicate and lithium disilicate. J. Phy. Rev. B 32, 1203 (1985)

49. Tang, T, Luo, DL: Density functional theory study of electronic structures in lithium silicates: Li2SiO3 and Li4SiO4. J. At. Mol. Sci. 1, 185 (2010)

50. Fang, RC: Solid State Spectroscopy. Chinese Science Technology University Press, Hefei (2003)

51. Zhang, Y, Shen, WM: Basic of Solid Electronics. Zhe Jiang University Press, Hangzhou (2005)

52. de Almeida, JS, Ahuja, R: Tuning the structural, electronic, and optical properties of Bex $Z n_{1-x} T e$ alloys. Appl. Phys. Lett. 89, 061913 (2006)

53. Bouhemadou, A: Khenata, Comput, $\mathrm{R}$ : Ab initio study of the structural, elastic, electronic and optical properties of the antiperovskite SbNMg 3. Mat. Sci. 39, 803 (2007)

54. Saniz, R, Ye, LH, Shishidou, T, Freeman, A: Structural, electronic, and optical properties of NiAl3: first-principles calculations. J. Phy. Rev. B. 74, 014209 (2006)

doi:10.1186/2228-5326-3-14

Cite this article as: Alemi et al:: Lithium metasilicate and lithium disilicate nanomaterials: optical properties and density functional theory calculations. International Nano Letters 2013 3:14.

\section{Submit your manuscript to a SpringerOpen ${ }^{\circ}$ journal and benefit from:}

- Convenient online submission

- Rigorous peer review

- Immediate publication on acceptance

- Open access: articles freely available online

- High visibility within the field

- Retaining the copyright to your article

Submit your next manuscript at $\gg$ springeropen.com 